\title{
Global costs of plant invasions must not be underestimated
}

\author{
Ana Novoa', Desika Moodley', Jane A. Catford ${ }^{2}$, Marina Golivets ${ }^{3}$, \\ Jennifer Bufford ${ }^{4}$, Franz Essl ${ }^{5}$, Bernd Lenzner ${ }^{5}$, Zarah Pattison ${ }^{6}$, Petr Pyšek ${ }^{1,7}$ \\ I Czech Academy of Sciences, Institute of Botany, Department of Invasion Ecology, CZ-25243, Prühonice, \\ Czech Republic 2 Department of Geography, King's College London, UK $\mathbf{3}$ Helmholtz Centre for Environmen- \\ tal Research GmbH - UFZ, Halle (Saale), Germany 4 Bio-Protection Research Centre, Lincoln University, \\ New Zealand 5 BioInvasions, Global Change, Macroecology-Group, Department of Botany and Biodiversity \\ Research, University Vienna, 1030 Wien, Austria 6 School of Natural and Environmental Sciences, Newcastle \\ University, Newcastle upon Tyne, UK $\mathbf{7}$ Department of Ecology, Faculty of Science, Charles University, Viničná \\ 7, CZ-128 44 Prague, Czech Republic \\ Corresponding author: Ana Novoa (novoa.perez.ana@gmail.com)
}

Academic editor: Kühn I | Received 10 September 2021 | Accepted 22 September 2021 | Published 13 October 2021

Citation: Novoa A, Moodley D, Catford JA, Golivets M, Bufford J, Essl F, Lenzner B, Pattison Z, Pyšek P (2021) Global costs of plant invasions must not be underestimated. NeoBiota 69: 75-78. https://doi.org/10.3897/neobiota.69.74121

The impacts of biological invasions have become a key focus of researchers in recent decades, leading to a rapid accumulation of evidence on economic losses associated with invasions. In a synthesis paper, Diagne et al. (2021) use a new database, InvaCost (Diagne et al. 2020), to quantify the global economic costs of biological invasions. They demonstrate that the global costs associated with invasive alien species are massive, at least US\$ 1.3 trillion between 1970 and 2017, and increasing rapidly. Such high costs emphasize the critical importance of preventing and controlling biological invasions. Their paper thus delivers an important and much needed contribution to invasion science, which can strengthen invasive alien species management and policy globally. However, the costs of plant invasions presented by Diagne et al. (2021) are substantially underestimated compared to those of vertebrate and invertebrate invasions, and with respect to the available literature. While Diagne et al. (2021) state that the reported costs have pronounced geographic and taxonomic gaps, we believe that their significant underestimation of plant costs in comparison with other taxonomic groups needs to be clarified, to correctly demonstrate the severity of plant

Copyright Ana Novoa et al. This is an open access article distributed under the terms of the Creative Commons Attribution License (CC BY 4.0), which permits unrestricted use, distribution, and reproduction in any medium, provided the original author and source are credited. 
invasions and guide appropriate prioritization, budgeting, and allocation of limited management resources.

Diagne et al. (2021) report that invasive alien plants contribute $1.5 \%$ of the total costs that can be attributed to a single taxonomic group between 1970 and 2017 (i.e. plants cost US\$ 8.9 billion out of a total of US\$ 591 billion attributable to plants, vertebrates or invertebrates). They acknowledge that the low representation of invasive alien plants "is probably due to a data deficiency in the current database". Indeed, subsequent updates to the InvaCost database revealed the unbalanced distribution of data entries among taxonomic groups in the version of the database used by Diagne et al. (2021) (InvaCost v1; https://doi.org/10.6084/m9.figshare.12668570.v1), as compared to subsequent versions. In particular, while the full InvaCost v1 database contained 98 data sources (publications, reports, etc.) on the costs of plant invasions out of 786 sources across all taxonomic groups, the first update, released in November 2020, added 623 sources to the full database, of which the majority (416 sources) included plant costs (InvaCost v3, https://doi.org/10.6084/m9.figshare.12668570.v3). Furthermore, the most recent version of the InvaCost database (https://doi.org/10.6084/ m9.figshare.12668570.v4) shows that over $80 \%$ of currently available data sources on the costs of plant invasions were absent from InvaCost v1. In comparison, less than half of the available sources on animal invasions were absent from InvaCost v1. While we appreciate that databases evolve as new information becomes available, and we welcome and applaud such updates, these numbers indicate a substantial discrepancy in the compilation of data for plants vs. animals in InvaCost v1. It seems inevitable that these biases in survey effort affected the numbers and proportional costs attributed to plants by Diagne et al. (2021).

Research published over the last 20 years also clearly shows that the global costs of plant invasions are much higher than the US\$ 8.9 billion reported by Diagne et al. (2021). For example, the total estimated cost of invasive alien plants in the South African fynbos alone is estimated at US\$ 11.8 billion (van Wilgen et al. 2001). In Europe, invasive alien plants have been found to cost at least $€ 3.8$ billion annually, accounting for $30 \%$ of total invasion costs in the continent (Kettunen et al. 2009). In another study, a single invasive alien plant, Ambrosia artemisiifolia (Asteraceae), has been reported to cost the European economy US\$ 4.5 billion annually (Bullock et al. 2012). This means that over four decades the cost of $A$. artemisiifolia would approximate that of the costliest taxa presented by Diagne et al. (2021), two mosquito species (Aedes aegypti and $A$. albopictus), which accounted for US\$ 148.7 billion between 1970 and 2017. Yet, no plant appears among the costliest taxa listed by Diagne et al. (2021). Similarly, the cost of invasive alien plants to the Australian economy within agricultural areas alone is estimated at US\$ 4 billion annually (Sinden et al. 2005), and aquatic invasive alien plants in 13 public lakes in Florida cause annual costs of US\$ 6 billion (Adams and Lee 2007). Plants also feature prominently among the world's " 100 of the worst" invasive alien species (Boudjelas et al. 2000), of which Euphorbia esula 
(Euphorbiaceae) ranks among the top ten economically most damaging species with a global cost of US\$ 7.3 billion between 1960 and 2020 (Cuthbert et al. 2021). This selection of studies alone - which is by no means exhaustive - illustrates that the real costs of plant invasions globally must be orders of magnitude higher than the US\$8.9 billion estimate reported by Diagne et al. (2021).

Available funding for effective invasive alien species management is generally scarce and resources need to be allocated efficiently and systematically (Dana et al. 2019). However, in reality budgets dedicated to environmental management are often prone to taxonomic bias (Mammola et al. 2020). By disproportionately underestimating plant costs, support for invasive alien plant management could be inappropriately deprioritized, which would have serious ecological and socioeconomic consequences. Continued updates to the InvaCost database will provide further clarity on the true known costs of invasive alien plants. However, as these examples illustrate, local and regional studies already provide strong evidence that invasive alien plants have caused substantial economic costs, which are comparable to those of invasive alien vertebrates or invertebrates. This important message needs to be highlighted to ensure that decisions associated with studying and managing biological invasions are based on the most accurate economic cost estimates, and resources are allocated on the basis of the best available science.

Therefore, we argue that the important message conveyed by Diagne et al. (2021) on the massive economic costs of biological invasions needs to be complemented to emphasize that (i) the costs of invasive alien plants are similar in magnitude to those incurred by invasive alien vertebrates or invertebrates; (ii) further work is needed to estimate and aggregate the costs of invasive alien plants worldwide; and (iii) preventing and controlling plant invasions should remain a key component of international, national and regional invasive alien species management and policy decisions.

\section{Acknowledgements}

AN, DM and PP were supported by EXPRO grant no. 19-28807X (Czech Science Foundation) and long-term research development project RVO 67985939 (Czech Academy of Sciences). JC has received funding from the European Research Council (ERC) under the European Union's Horizon 2020 research and innovation programme (grant agreement No. [101002987]). BL, FE, and MG were funded through the 20172018 Belmont Forum and BiodivERsA joint call for research proposals, under the BiodivScen ERA-Net COFUND programme, and with the funding organisations FWF (project no I 4011-B32 - BL, FE) and BMBF (01LC1807C - MG). JB was supported by the Marsden Fund Council from New Zealand Government funding, managed by Royal Society Te Apārangi and by a Tertiary Education Commission grant to the BioProtection Research Centre. 


\section{References}

Adams DC, Lee DJ (2007) Estimating the Value of Invasive Aquatic Plant Control: A Bioeconomic Analysis of 13 Public Lakes in Florida. Journal of Agricultural and Applied Economics 39: 97-109. https://doi.org/10.1017/S1074070800028972

Boudjelas S, Browne M, De Poorter M, Lowe S (2000) 100 of the world's worst invasive alien species: a selection from the Global Invasive Species Database. https://www.iucn. org/content/100-worlds-worst-invasive-alien-species-a-selection-global-invasive-speciesdatabase

Bullock JM, Chapman D, Schafer S, Roy D, Girardello M, Haynes T, Beal S, Wheeler B, Dickie I, Phang Z, Tinch R, Čivić K, Delbaere B, Jones-Walters L, Hilbert A, Schrauwen A, Prank M, Sofiev M, Niemelä S, Räisänen P, Lees B, Skinner M, Finch S, Nrough C (2012) Assessing and Controlling the Spread and the Effects of Common Ragweed in Europe.

Cuthbert R, Diagne C, Haubrock P, Turbelin A, Courchamp F (2021) Research Square Are the "100 of the world's worst" invasive species also the costliest? Research Square [In Review]. https://doi.org/10.21203/rs.3.rs-227453/v1

Dana ED, García-de-Lomas J, Verloove F, Vilà M (2019) Common deficiencies of actions for managing invasive alien species: a decision-support checklist. NeoBiota 48: 97-112. https://doi.org/10.3897/neobiota.48.35118

Diagne C, Leroy B, Gozlan RE, Vaissière A-C, Assailly C, Nuninger L, Roiz D, Jourdain F, Jaric I, Courchamp F (2020) InvaCost: References and description of economic cost estimates associated with biological invasions worldwide. figshare. https://doi.org/https://doi. org/10.6084/m9.figshare.12668570.v4

Diagne C, Leroy B, Vaissière A-C, Gozlan RE, Roiz D, Jarić I, Salles J-M, Bradshaw CJA, Courchamp F (2021) High and rising economic costs of biological invasions worldwide. Nature 592: 571-576. https://doi.org/10.1038/s41586-021-03405-6

Kettunen M, Genovesi P, Gollasch S, Pagad S, Starfinger U, ten Brink P, Shine C (2009) Technical support to EU strategy on invasive species (IAS) - Assessment of the impacts of IAS in Europe and the EU (final module report for the European Commission). Brussels.

Leroy B, Kramer A, Vaissière A, Courchamp F, Diagne C (2020) Analysing global economic costs of invasive alien species with the invacost $\mathrm{R}$ package. bioRvix. https://doi. org/10.1101/2020.12.10.419432

Mammola S, Riccardi N, Prié V, Correia R, Cardoso P, Lopes-Lima M, Sousa R (2020) Towards a taxonomically unbiased European Union biodiversity strategy for 2030. Proceedings of the Royal Society B - Biological Sciences 287: 20202166. https://doi.org/10.1098/ rspb.2020.2166

Sinden J, Jones R, Hester S, Odom D, Kalisch C, James R, Cacho O, Griffith G (2005) The economic impact of weeds in Australia. Plant Protection Quaterly 20: 25-32.

van Wilgen BW, Richardson DM, Le Maitre DC, Marais C, Magadlela D (2001) The economic consequences of alien plant invasions: Examples of impacts and approaches to sustainable management in south Africa. Environment, Development and Sustainability 3: 145-168. https://doi.org/10.1023/A:1011668417953 